\title{
Rede social e comunicação ubíqua: o que podemos aprender com Black Mirror?*
}

Social network and ubiquitous communication: what can we learn from Black Mirror?

Red social y comunicación ubicua: lo que podemos aprender con Black Mirror?

\author{
DILTON RIBEIRO COUTO JUNIOR (Da \\ ROSEMARY DOS SANTOS Db \\ LUCIANA VELLOSODC
}

\section{Resumo}

Este texto busca tecer reflexões em torno de práticas sociais mediadas pelo digital em rede retratadas no episódio intitulado Queda Livre da série Black Mirror. A proposta é discutir a relação entre interconectividade, popularidade e visibilidade na era da comunicação ubíqua com a intenção de ressignificar nossa própria experiência humana, que vem sendo cada vez mais mediada pelos processos comunicacionais digitais. Buscar inspiração na ficção de Black Mirror pode se constituir como um caminho potente para refletirmos sobre nossa humanização numa era marcada pela intensa produção e compartilhamento de dados entre usuárias/os geograficamente dispersas/os. Para além do caráter ficcional da série e das situações expressas no episódio, há ali um alerta para os extremos a que o uso dos dispositivos digitais pode nos levar, fazendo-nos refletir sobre a importância de

\footnotetext{
${ }^{*} O$ texto contém SPOILERS de um dos episódios da série Black Mirror, ou seja, informações que revelam inúmeros acontecimentos da trama.

aUniversidade do Estado do Rio de Janeiro (UERJ/FEBF), Duque de Caxias, RJ, Brasil. Doutor em Educação (ProPEd/UERJ), e-mail: junnior_2003@yahoo.com.br

bUniversidade do Estado do Rio de Janeiro (UERJ/FEBF), Duque de Caxias, RJ, Brasil. Doutora em Educação (ProPEd/UERJ), e-mail: rose.brisaerc@gmail.com

'Universidade do Estado do Rio de Janeiro (UERJ), Rio de Janeiro, RJ, Brasil. Doutora em Educação (ProPEd/UERJ), e-mail: lucianavss@gmail.com
} 
se colocar em prática uma educação que amplie nossa visão sobre o potencial da interconectividade e seus desdobramentos. Que esses novos fenômenos ciberculturais nos permitam tecer reflexões profícuas para uma melhor compreensão das práticas sociais contemporâneas, pelas relações que vimos estabelecendo com as redes sociais, com a emergência da comunicação ubíqua e com a ressignificacão de novas experiências sociais que emergem atravessadas pelo digital em rede na vida cotidiana.

Palavras-chave: Redes sociais. Comunicação ubíqua. Conectividade. Black Mirror.

\begin{abstract}
This text aims to reflect upon social practices mediated by digital network portrayed in the episode "Nosedive" from the television series Black Mirror. The proposition is to discuss the relationship between interconnectivity, popularity, and visibility in the age of ubiquitous communication. We aim to resignify our own human experience that is being more and more mediated by digital communication. Seeking inspiration on the fiction of Black Mirror can constitute a potent path to reflect upon our humanization in an era marked by the intense production and intense sharing of data among geographically dispersed users. In addition to the fictional character of the series and the situations shown in the episode, there is an alert for the extremes caused using of digital devices. Therefore, making us think about the importance of an education that broadens our view on the potential of interconnectivity and its consequences. We hope that these new cybercultural phenomena allow us to make fruitful reflections for a better understanding of contemporary social practices, the relationships we have established with social networks, the emergence of ubiquitous communication, and the re-signification of new social experiences that emerge through digital networking in everyday life.
\end{abstract}

Keywords: Social networking. Ubiquitous communication. Connectivity. Black Mirror.

\title{
Resumen
}

Este texto busca tejer reflexiones en torno a prácticas sociales mediadas por el digital en red retratadas en episodio titulado Queda Libre de la serie Black Mirror. La propuesta es discutir la relación entre interconectividad, popularidad y visibilidad en era de la comunicación ubicua con la intención de resinificar nuestra propia experiencia humana que ven siendo cada vez más mediada pelos procesos comunicacionales digitales. Buscar inspiración en la ficción de Black Mirror puede constituirse como un camino potente para reflexionar sobre nuestra humanización en una era marcada por una intensa producción y compartimiento de datos entre usuarias/os geográficamente dispersas/os. Para además del carácter ficcional de la serie y das situaciones expresas en episodio, ha allí un alerta para los extremos que el uso de los dispositivos digitales pueden nos llevar, haciéndonos reflectar sobre la importancia de una educación que amplié nuestra visión sobre el potencial de la interconectividad y sus desdoblamientos. Que esos nuevos 
fenómenos ciberculturales nos permitan tejer reflexiones provechosas para una mejor comprensión de las prácticas sociales contemporáneas, por las relaciones que vimos estableciendo con las redes sociales, con la emergencia de la comunicación ubicua y con la resignificación de nuevas experiencias sociales que emergen atravesadas por el digital en red en la vida cotidiana.

Palabras clave: Redes sociales. Comunicación ubicua. Conectividad. Black Mirror.

A meu ver, os otimistas acreditam que este mundo é o melhor possivel, ao passo que os pessimistas suspeitam que os otimistas podem estar certos. Mas acredito que essa classificação binária de atitudes não é exaustiva. Existe uma terceira categoria: pessoas com esperança. Eu me coloco nessa terceira categoria. De outra forma, não veria sentido em falar e escrever.

(Zygmunt Bauman).

\section{Introdução}

Redes sociais, internet, aplicativos (App), mobilidade, ubiquidade, para citar algumas, são palavras-chave muito populares atualmente que revelam a especificidade de uma época nitidamente marcada por práticas cotidianas exercidas cada vez mais através da mediação das tecnologias digitais em rede. Caminhamos com Bauman no argumento acima e nos colocamos como sujeitos esperançosos para (re)pensar as práticas sociais, buscando apresentar um olhar atento e sensível ao longo da tessitura de um texto que busca respostas não conclusivas para os fenômenos sociais engendrados pela cibercultura. Dessa forma, para compreender como se articulam as tecnologias digitais no momento atual, necessitamos levar em consideração a cultura contemporânea e sua dimensão informativa e digital (WEBER; SANTOS; SANTOS, 2013). Para além da suposta neutralidade, as tecnologias digitais em rede fazem parte de um universo complexo, de mudanças cada vez mais velozes das relações entre as pessoas para a produção de sua existência no mundo contemporâneo.

No cenário caracterizado pelo que tem se denominado cultura da convergência (JENKINS, 2009) e mais recentemente, cultura da conexão (JENKINS, GREEN e FORD, 2014), temos refletido sobre como estas relações de conexões, aproximações e afastamentos têm se dado. No que tange à ideia de uma suposta convergência 
cultural, Jenkins (2009) discute sobre o fluxo de conteúdos que, através de múltiplas plataformas midiáticas, se desloca virtualmente em busca do entretenimento que desejam. Ainda de acordo com o autor, a convergência se opõe à ideia de um processo tecnológico que une múltiplas funções dentro do mesmo aparelho. A convergência está mais relacionada com uma mudança cultural que incentiva consumidores a procurarem mais informações e a realizarem mais conexões em meio a conteúdos de mídia dispersos (JENKINS, 2009).

No cenário sócio-técnico contemporâneo, Jenkins (2009) e Jenkins, Green e Ford (2014) chamam a atenção para a cultura participativa para reforçar que, para além dos aparelhos e equipamentos, por mais sofisticados que sejam, a mudança ocorre dentro das mentes das/os consumidoras/es, cada vez mais partícipes dos movimentos de mudanças. Produzir e compartilhar são palavras-chave que evidenciam a força de dinâmicas comunicacionais digitais que agregam sujeitos geograficamente dispersos em torno de uma mesma rede gigantesca de troca de informações constante. Essa dinâmica comunicacional envolve a participação de internautas de todos os cantos do globo que, cada vez mais, interagem a partir de dispositivos digitais em conexão contínua (ubiquidade), ou seja, permanecem interconectadas/os na medida em que circulam pelos espaços físicos da cidade (FERREIRA; COUTO JUNIOR, 2018).

A ubiquidade é a capacidade da/o internauta de participar ativamente de diferentes intercâmbios de experiências, comunicando-se com outras pessoas ao “estar presente em vários lugares ao mesmo tempo" (SILVA; ALVES, 2018, p. 20). Neste contexto, conforme argumentam Pretto e Assis (2008), entendemos que as apropriações da cultura digital se tornam de grande relevância, uma vez que ela se relaciona intrinsecamente a um processo crescente de reorganização das relações sociais mediadas pelas tecnologias digitais, afetando de diferentes modos, em maior ou menor escala, os mais diversos aspectos da ação humana. Não existe ubiquidade sem a relação estabelecida pelos sujeitos com os dispositivos digitais móveis relação essa responsável pela reconfiguração do tempo-espaço. Dito isso, os processos comunicacionais ubíquos têm transformado a forma como as informações são produzidas, compartilhadas, armazenadas e acessadas pelas/os usuárias/os (SANTAELLA, 2018). 
Observamos modelos híbridos de circulação em que um mix de forças indica o que será compartilhado, de modo que as decisões que tomamos por acessar, produzir, compartilhar ou não certos conteúdos está remodelando o próprio cenário midiático. Embora não atingindo a todos/as do mesmo modo, é notório o quanto as mudanças que vivenciamos no contexto informacional, da distribuição para a circulação, modifica a percepção de um público que é cada vez mais ativo e capaz de interagir e se conectar com outros grupos para além de proximidades geográficas. Com Santos e Carvalho (2018) entendemos que a cibercultura oportuniza às/aos usuárias/os participar de processos de interação colaborativos, propiciando que as ideias sejam "debatidas, confrontadas, tecidas e aprimoradas, com vistas a ir além da condição de consumidor de conteúdos, passando também a criar, disponibilizar, discutir e compartilhar suas autorias em rede" (SANTOS; CARVALHO, 2018, p. 34).

Dado o pano de fundo mencionado anteriormente, com este texto nos inspiramos nos temas atuais da cibercultura a partir da análise do episódio Queda Livre (Nosedive em inglês) da série Black Mirror. Criada pelo britânico Charlie Brooker, a série foi lançada em 2011 e desde então é considerada pela crítica como uma das mais intrigantes no cenário televisivo por retratar problemas atuais a partir dos usos das tecnologias digitais. Em 2012, a série britânica ganhou o prêmio de Melhor Filme/Minissérie da TV no International Emmy Awards, sendo que alguns anos depois a atriz Bryce Dallas Howard recebeu uma indicação ${ }^{1}$ no Screen Actors Guild Award pela primorosa atuação no episódio Queda Livre. As temáticas que emergem evidenciam como parte dos nossos esforços de compreender o quanto a relação das pessoas com os artefatos tecnológicos conectados à internet vem ressignificando a forma como produzimos novos sentidos culturais com outras/os usuárias/os geograficamente dispersas/os. Essa relação, mediada pelas tecnologias digitais, apresenta implicações para os processos de ensinar-aprender porque hoje em dia é "praticamente impossível falar da nossa existência no mundo atual sem os aparatos técnicos que acabaram por modificar a própria natureza humana" (JOBIM E SOUZA, 2002, p. 75). Natureza esta que será aqui discutida acompanhando a

\footnotetext{
${ }^{1}$ Cf. <https://bit.ly/2ODI8KI>. Acesso em: 14 mai. 2018. 
personagem Lacie Pound, apresentada a seguir, que é em torno de quem as situações do episódio gravitam.

Diversas/os pesquisadoras/es já se debruçaram analiticamente sobre a série Black Mirror com o objetivo de explorar a forma como a emergência de determinados recursos tecnológicos vem favorecendo mudanças sociais significativas. Nesse contexto, vale mencionar a discussão de textos que refletiram sobre: a) a sociedade da vigilância a partir do sistema de avaliação adotado no aplicativo Uber $^{2}$ (BRAZ; MONTE; CARVALHO, 2017; BRAGA; EVANGELO, 2017); b) aspectos referentes ao controle, ubiquidade midiática e a construção de subjetividade (TRENTO; VENANZONI, 2013); c) a sociedade do espetáculo (LIMA; FERNANDES, 2016), além de outros possíveis paralelos interpretativos realizados mediante a análise da série britânica e a vida cotidiana mediada pelo digital em rede (MADEIRA; SILVA; RIOS, 2017). O que esses trabalhos apresentam em comum é a necessidade de trazer à tona o quanto os episódios fictícios narrados na série Black Mirror se caracterizam como potentes disparadores reflexivos que nos auxiliam a (re)pensar nossa própria condição humana na pós-modernidade. Tal condição nos coloca no desafio de entender o quanto o digital em rede vem possibilitando a produção de múltiplas narrativas tecidas na vida contemporânea e que estão ressignificando o processo de constituição de nossas próprias subjetividades.

Os inúmeros cenários cotidianos apresentados no episódio Queda Livre de Black Mirror são o foco de análise desse texto. Interconectividade, popularidade, vigilância, controle e punição são alguns dos temas tratados ao longo de um episódio que nos permitiu estabelecer inúmeros apontamentos sobre as práticas sociais cotidianas, principalmente aquelas que vêm sendo estabelecidas nos espaços urbanos. A partir desses temas explorados no episódio, buscamos tecer reflexões engendradas pela relação das pessoas com as redes sociais em tempos de comunicação ubíqua, guiando-nos pelas severas críticas de Black Mirror frente aos usos das tecnologias digitais em rede na vida cotidiana das pessoas. Para isso, nos apropriamos dos estudos

\footnotetext{
2 Uber é uma empresa multinacional americana fundada em 2009 que presta serviços na área do transporte privado. Através do aplicativo (App) de transporte do mesmo, a/o usuária/o solicita motoristas com base em sua localização, usufruindo de um serviço semelhante ao do táxi tradicional.
} 
de pesquisadoras/es que investigam os fenômenos da cibercultura, principalmente enfatizando a discussão em torno dos processos comunicacionais digitais móveis (LEMOS, 2010) e da ubiquidade (conexão constante) (SANTAELLA, 2013) na tessitura das reflexões desse texto.

Com esse texto, ao buscarmos tecer apontamentos inconclusivos sobre o episódio Queda Livre, nos interessa provocar discussões que ressignifiquem a forma como enxergamos as tecnologias digitais em rede. Isso significa nos lançarmos no desafio de problematizar nossas próprias experiências interativas e comunicacionais mediadas pelo digital, na tentativa singela de formularmos reflexões instigantes no lugar de responder prontamente aos inúmeros questionamentos que as práticas cotidianas nos apresentam. Concordamos com Louro (2007, p. 237), para quem argumenta que “quando 'recheamos' nossos textos de questões, provocamos um deslizamento na fonte de autoridade e instigamos ou convidamos o/a leitor/a a formular respostas às indagações feitas". Dessa forma, considerando que os processos comunicacionais em rede encontram-se em constante reconfiguração, seria incoerente fornecermos às/aos leitoras/es respostas definitivas às possíveis análises interpretativas engendradas pelas experiências sociais mediadas pelo digital.

\section{Cenários cotidianos apresentados no episódio Queda Livre de Black Mirror}

Nossas vidas em tela, expostas, transformadas em palco para a teatralização do eu. Teatralização que, se por um lado pode reafirmar a artificialidade de nossas interações cotidianas, também nos conforta e nos parece transmitir uma certa promessa de que estamos lidando de modo mais transparente uns com os outros. Sibilia (2015) já advertia sobre nossa preocupação em relação a um contexto de sentimentos de falta de segurança individual e coletiva, algo que parece se minimizar com a oferta de dispositivos tecnológicos específicos para que possamos nos sentir protegidas/os. São sistemas de monitoramento que vigiam prédios, lojas, elevadores, ruas, quartos de casas e salas de aula. Com tais alterações em termos de uso de espaços e processamento de dados digitais, nossas subjetividades já têm sido afetadas por estes 
dispositivos de controle que colocam em suspenso as supostamente tão bem demarcadas esferas pública e privada.

Este esgarçamento de fronteiras entre público e privado fica bastante explícito ao nos determos na análise mais apurada do episódio Queda Livre (Nosedive em inglês), da série Black Mirror. Ali naquele contexto, estas distinções parecem explicitar radicalmente a diluição da clássica noção de esfera pública (transformada agora também em uma extensão do mundo virtual), supondo que subjetividades e corpos contemporâneos serão redefinidos em relação a questões como ser humano, natureza e vida (SIBILIA, 2015). Iniciamos então analisando o episódio.

Enquanto se exercita no início da manhã, Lacie Pound (personagem interpretado por Bryce Dallas Howard) encontra-se interconectada com outras pessoas geograficamente dispersas através do uso de fones de ouvido, smartphone, além do implante ocular que a permite vivenciar a experiência da realidade aumentada. $\mathrm{Na}$ medida em que Lacie percorre as ruas quase vazias de sua vizinhança, permanece praticamente o tempo todo com os olhos fixados na tela do celular, com exceção de alguns segundos, quando interage com uma outra pessoa na rua, também praticando exercícios com o celular em mãos. O exercício em si fica em segundo plano comparado com a atenção que ela dedica às atividades sociais realizadas através do smartphone. Assim se inicia o episódio intitulado Queda Livre da série Black Mirror. Com cerca de 60 minutos de duração, a história gira em torno da vida cotidiana de Lacie Pound, mais especificamente na tentativa dela de se "qualificar" o suficiente para conseguir atingir a meta de 4.5 estrelas na sua rede social, pré-requisito necessário para que ela consiga ser a nova moradora de um luxuoso e badalado condomínio residencial. Afinal, o que podemos aprender com Black Mirror?

\section{Interconectividade, popularidade e visibilidade: o show de Lacie na rede social}

Um dos aspectos que merecem nossa atenção ao discutir a série Black Mirror é a questão da visibilidade e da privacidade. Estamos lidando com um contexto no qual todas as nossas ações cotidianas são vistas, avaliadas e mensuradas para que, deste 
modo, possamos ser mais ou menos aceitos por nossos pares. Keen (2012) apresenta a visibilidade como uma armadilha na qual nós mesmos aceitamos fazer parte, mesmo sem nos darmos conta dessas implicações. O autor indaga sobre o que Black Mirror antecipa: "qual será o destino quando você, eu e todo mundo estivermos presos, para o bem ou para o mal, numa rede radicalmente transparente de 'compartilhamento sem atrito’ que acabou com o segredo e a solidão?” (KEEN, 2012, p. 75).

Ainda não estamos vivenciando efetivamente tal imersão, embora Mark Zuckerberg já apresente a intenção de reunir na rede social Facebook nossas informações de modo a serem mais facilmente compartilhadas, como se esta suposta facilidade a tudo o que envolve nossas vidas tornasse o mundo um lugar melhor (KIRKPATRICK, 2011). Dentro de dez anos, a expectativa é a de que redes online como SocialEyes, Hotlist, Open Graph, Facebook, SocialCam, Waze, TripIt, Plancast e Into.now permita às/aos suas/seus usuárias/os ter livre acesso a tudo o que se lê, compra, come e, de modo mais complexo, até ao que cada um pensa (KEEN, 2012). A questão paradoxal que se coloca é: em dez anos podemos pensar em eliminar nossas solidões, compartilhando tudo com todas/os. Contudo, indagamos: onde o anseio pelo compartilhar momentos tenciona e esbarra com a invasão da privacidade e do que queremos guardar conosco?

Diante da letra da canção de Chico Buarque, "a dor da gente não sai no jornal"3, vale refletirmos sobre até que ponto queremos que estas nossas dores, nossos momentos mais introspectivos e nossas dificuldades para lidar com as tantas complexidades das interações sociais sejam expostas e divididas com quem quer que tenha acesso a nossos dados. Em um mundo no qual o que prevalece é o lado mais escancarado dos dispositivos tecnológicos, muito bem retratado em Black Mirror, temos o exemplo da cena do aeroporto, na qual Lacie interage com a funcionária do guichê de atendimento. O voo foi cancelado e ela não tem estrelas suficientes para embarcar num outro voo. A personagem fica preocupada porque pode acabar perdendo o ensaio do casamento da amiga, então agride verbalmente a atendente do guichê, que convoca o segurança do aeroporto. O segurança chega com um smartphone para punir Lacie, reduzindo seu número de estrelas. Eis então um

\footnotetext{
${ }^{3}$ Trecho da canção "Notícia de Jornal”, de Chico Buarque (1975). 
exemplo de como as mídias sociais, em seu uso visto como mais "apocalíptico", para nos apropriarmos aqui dos termos de Eco (1993), pode, a despeito de todas as promessas comunitárias, nos dividir, fragmentar e hierarquizar, estimulando o que Walter Kirn (2010) identifica como uma "sociedade fragmentária". Em nossa ânsia pela igualdade, vamos nos tornando cada vez mais desiguais.

A cena de Lacie no aeroporto, assim como as demais experiências sociais retratadas no episódio, evidencia o quanto "a cibercultura não é uma cultura própria de um segmento, não escolhemos se queremos estar dentro ou fora dela porque trata de uma revolução paradigmática" (D’ÁVILA; SANTOS, 2014, p. 113). Essa revolução mediada pelo digital em rede é representada no episódio de forma que todas as personagens encontram-se interconectadas, produzindo e compartilhando informações que estão permanentemente sob o olhar vigilante da/o outra/o. Neste contexto, não há como negar o quanto essa vigilância é fruto de um sistema de avaliação baseado na atribuição de número de estrelas a cada usuária/o. Esse sistema colabora na promoção de práticas sociais desiguais, impedindo que as pessoas menos "populares" possam usufruir, por exemplo, dos melhores serviços da sociedade.

Conforme evidenciado no episódio, a interconectividade entre as personagens propicia que o sistema de estrelas seja constituído, ao mesmo tempo em que desencadeia práticas sociais impulsionadas pelo desejo por maior visibilidade e popularidade da/o usuária/o na rede. Neste contexto, é possível articular essa prática da avaliação por estrelas com o ato de "curtir" postagens em redes sociais como o Facebook. Recuero (2014), Couto Junior (2017) e Ferreira (2014) discutem a ideia das "curtidas" nas diferentes redes sociais, reforçando o quanto isso "valida" o que o outro tem a dizer, contribuindo para que as/os autoras/es da "curtida" tenham seus nomes vinculados à postagem. Afinal, cabe refletirmos: "o que torna uma postagem digna de ser 'curtida'? E o que impede que uma postagem seja 'curtida'?” (COUTO JUNIOR, 2017, p. 104). Não é nossa intenção responder a essas indagações, apenas frisar o quanto o conteúdo que produzimos e compartilhamos através das diversas redes sociais encontram-se constantemente sob o olhar atento (e crítico!) das/os usuárias/os que constituem nossas redes. Afinal, as palavras/imagens que produzimos e postamos revelam pistas de nossas formas de pensar. 
Conforme indaga Primo (2013, p. 15), "agora que as mídias digitais foram de fato popularizadas (para se evitar a simplificação do termo 'democratização'), será que os relacionamentos realmente se horizontalizaram em um platô sem hierarquias?". Se tomarmos como exemplo o sistema de avaliação do episódio Queda Livre, tudo indica que não, uma vez que práticas comunicacionais mais horizontalizadas não poderiam ser sustentadas numa lógica que envolve o anseio de suas/seus usuárias/os por maiores níveis de popularidade. Ainda que não possamos desconsiderar a liberdade de expressão promovida pelas interfaces fáceis e relativamente baratas da cibercultura, não há como negar o quanto o digital em rede também vem impulsionando uma onda na qual "todos querem lucrar com propaganda, todos sonham com a fama, todos querem explorar as mídias sociais como fonte de renda” (PRIMO, 2013, p. 20).

Uma vez que o capital se reinventa no contexto das práticas sociais ciberculturais (PRIMO, 2013), cabe a nós reinventarmos outras formas de (re)existências capazes de potencializar nossa própria condição de humano dentro de uma perspectiva dialógica e alteritária no qual todas/os as/os usuárias/os, independente do número de estrelas, importam (COUTO JUNIOR; OSWALD, 2017). Na investigação sobre os usos culturais das redes sociais da internet, temos percebido uma espécie de organismo hiperconectado, coletivamente construído e altamente complexo. Diante de tais alterações, Jensen (2010) reflete sobre a questão do suporte e da interação diária das/os usuárias/os, argumentando que a comunicação em rede deve questionar não só o que a rede social faz com as pessoas, mas também o que as pessoas fazem com ela.

Fantin (2017) chama atenção para a importância do uso responsável das/os usuárias/os ao produzir e compartilhar conteúdo em/para a rede, atentando para a necessidade de que possamos refletir sobre a confiabilidade das informações buscadas, além dos cuidados éticos envolvendo o uso do registro fotográfico e/ou audiovisual. Concordamos com o pensamento da autora, ao afirmar que esses registros necessitam "contemplar o consentimento das pessoas envolvidas" (FANTIN, 2017, p. 71). Em uma sociedade cada vez mais interconectada, que produz, posta e "curte" arquivos constantemente, conforme a crítica feita pelo episódio Queda Livre, esse compromisso ético envolvendo o consentimento do outro na troca de dados/arquivos requer um cuidado redobrado na era da comunicação móvel. Isso 
porque, ao ser digitalizada, a informação consegue multiplicar-se facilmente na medida em que é dinamicamente compartilhada entre usuárias/os conectados à rede (COUTO JUNIOR, 2015). Diante da facilidade com a qual conseguimos tornar visível nossas próprias histórias através dos bits de informação produzidos e compartilhados, a personagem Lacie evidencia o quanto sua popularidade e visibilidade na rede social são frutos de um intenso investimento pessoal alimentado pelo desejo de permanecer interconectada com outros sujeitos.

Vale destacar ainda que, se por um lado muitos compartilhamentos e postagens potencializam os laços sociais e afetivos entre internautas (COUTO JUNIOR, 2013), por outro lado também é evidente conversas inflamadas realizadas entre grupos de sujeitos (RECUERO, 2013), o que nos convida a refletir permanente sobre a forma como estamos ocupando as redes sociais digitais. Essas redes são bons exemplos de espaços de negociação de sentidos, o que significa que as mensagens trocadas nem sempre são harmoniosas, porque estamos ocupando um espaço constituído de pessoas com histórias de vida diferentes e que pertencem a contextos socioculturais dos mais diversos. Não obstante, nosso desafio com as redes sociais é afetar e nos deixar afetar por outras pessoas com a proposta de "usar as tecnologias digitais em rede, dispositivos móveis e demais artefatos culturais como formas de criação de conhecimento e cultura” (SANTOS, WEBER, 2013, p. 300).

Afinal, por que esses dispositivos móveis conectados à internet fascinam cada vez mais as/os usuárias/os? Acreditamos que uma possível forma de responder esta pergunta seria por conta das amplas possibilidades interativas/comunicacionais engendradas pela convergência de jogos, vídeos, fotos, músicas e textos na manutenção de uma comunicação ubíqua via aplicativos de redes sociais, Whats $A p p$ e chamadas telefônicas. Não são mais simplesmente dispositivos que permitem a comunicação oral, mas sim um sistema de comunicação multimodal e portátil, um sistema de comunicação ubíqua para leitoras/es que transitam por entre múltiplas ambiências formativas através da conexão contínua com a rede. Antes dos dispositivos móveis, a conexão em redes dependia de uma interface fixa, os computadores de mesa (desktop). A entrada nas redes implicava que a/o usuária/o estivesse fisicamente parado à frente do computador. Agora, ao carregar consigo um dispositivo móvel, a mobilidade se torna dupla: mobilidade informacional e 
mobilidade física da/o usuária/o (LEMOS, 2007). Para navegar de um ponto a outro das redes informacionais, nas quais se entra e se sai para múltiplos destinos, a/o usuária/o também pode estar em movimento. $\mathrm{O}$ acesso passa a se dar em qualquer momento e em qualquer lugar. Acessar e enviar informações, transitar entre elas, conectar-se com as pessoas, coordenar ações em grupos, compartilhar arquivos, marcar e organizar eventos (FERREIRA; COUTO JUNIOR, 2018). Assim, o ciberespaço fundiu-se de modo indissolúvel com o espaço físico, criando o que Santaella (2007) denomina de espaço intersticial, híbrido e misturado.

No livro "Isso (não) é muito Black Mirror," Lemos (2018) analisa o episódio Queda Livre e argumenta sobre os desafios dos próximos anos que vão além da dinâmica de pontuação das redes sociais, que provavelmente devem migrar para sistemas mais amplos que atingirão outras áreas da vida pessoal e coletiva. Para o autor, além dos pontos e curtidas nas redes sociais, precisamos ficar igualmente atentas/os para garantir liberdades de ação, a desprogramação algorítmica, a garantia de proteção de privacidade e do anonimato em meio a performances dos objetos e dos dados, não necessariamente ligados a uma lógica de pontos. Para Lemos (2018), certamente esse é o episódio que mais se aproxima do nosso presente e traz algumas questões interessantes para que possamos refletir na sociedade atual. Cabem então indagações como:

o esquema de pontuação servirá para o futuro? Podemos reduzir os problemas da cultura digital a esse tipo de monetização das redes sociais? O que incomoda no episódio é a estética cheia de clichês de um futuro que, mais uma vez, se parece muito mesmo com o presente aqui apresentado. E assim ele será? (LEMOS, 2018, p. 89).

Com essas questões, Lemos (2018) nos provoca a pensar temas importantes que deverão nos inspirar para pesquisas futuras sobre vigilância, capital social, mídias locativas, objetos inteligentes e como os usos desses artefatos culturais podem potencializar formas outras de inventar ações e reflexões na articulação das relações sociais mediadas pelo digital em rede.

Entendendo que atualmente a conexão está nas pessoas e que cotidianamente nos deparamos com usuárias/os conectadas/os nos mais variados contextos socioculturais, estar nas redes tornou-se uma condição humana. E pensar esse cenário e suas influências na vida e formação das pessoas é fundamental para a nossa 
construção social e pessoal, como praticantes da cibercultura. Com as transformações ocorrendo de maneira tão rápida é possível perceber/sentir/viver as mudanças que os usos dessas tecnologias digitais estão provocando na sociedade. A imersão cada vez maior no ciberespaço traz novos modos de ser e estar no mundo, a maneira que vivemos se configura em novos formatos, construímos conhecimentos de outras formas e a maneira como lidamos com a pluralidade de redes e tecnologias disponíveis despertam em nós outras aprendizagens e necessidades.

No contexto das dinâmicas ciberculturais vimos desenvolvendo novos hábitos e práticas sociais, novas relações com os espaços e com a forma como produzimos, acessamos e consumimos informações. Tais rearranjos vão se construindo muito em consonância com o clássico argumento da "sociedade do espetáculo", desenvolvido nos idos da década de 1960 por Guy Debord (1997). Dessa forma, vão se ressignificando através das tecnologias digitais móveis, talvez de modo mais sutil, mas não menos acentuado. Espetáculo aqui é entendido como a relação social estabelecida pelas pessoas com as diferentes imagens. Somos cada vez mais o resultado provisório de identificações múltiplas, contextuais e negociadas. Nesta perspectiva, concordamos com Maffesoli (2017), ao destacar que estas reorganizações societárias traduzidas em efervescências cotidianas é algo que os observadores sociais terão cada vez mais que considerar em suas análises das práticas culturais.

\section{Que possamos aprender com os desvios: palavras inconclusivas}

No meio do caminho tinha uma pedra tinha uma pedra no meio do caminho tinha uma pedra no meio do caminho tinha uma pedra. (Carlos Drummond de Andrade) ${ }^{4}$

Concluímos retomando o título do episódio da série em questão fazendo uma analogia com o poema de Drummond. Entendemos esta ideia da "queda livre" como uma metáfora para discutir algo que nos humaniza, nossos tropeços, nossas falhas e

\footnotetext{
${ }^{4}$ In: MORICONI, Í. Os cem melhores poemas brasileiros do século (org.). Rio de Janeiro: Objetiva, 2001.
} 
nossas limitações, ou seja, o que nos constitui como seres humanos imersos numa sociedade estruturada por tecnologias digitais em rede. Se "no meio do caminho tinha uma pedra", como mencionado por Drummond em seu poema "No meio do caminho" (1928), Lacie tropeçou na pedra, nós tropeçamos diversas vezes. Contudo, acreditamos que no meio da metafórica "pedra" podemos encontrar novos caminhos. Que possamos aprender com os desvios, com o percurso de uma caminhada (ainda) não pavimentada que não apresenta destino pré-definido tampouco a presença de $\operatorname{pedra}(\mathrm{s})$.

Ao atentarmos para a ampla gama de discussões propiciada pelo episódio analisado e relacionando tais discussões com o uso de redes sociais, observamos que os relacionamentos humanos mediados pelo digital em rede não podem ser simplesmente mensurados pelo número de curtidas e a quantidade de postagens realizadas. Nesse sentido, em entrevista concedida ao Projeto Fronteiras do Pensamento $^{5}$, em 23 de julho de 20116, Zygmunt Bauman comenta este aspecto da fluidez dos relacionamentos contemporâneos ao narrar que certa vez um jovem o interpelou se gabando por ter feito mais de quinhentos amigos em um dia, por intermédio de sua rede social. Bauman se surpreendia pois, em toda sua vida, aos 86 anos, não tinha quinhentos amigos. Aproveita a conversa para discutir as diferentes concepções de amizade que permeavam a fala do jovem e a sua, discutindo a atual existência das redes de sociabilidade, que na sua juventude eram substituídas por laços e comunidades. Apresenta a distinção de que as comunidades nos precedem, pois nascemos nelas. Já as redes são feitas e desfeitas através das ações de conectar e desconectar. Bauman prossegue indicando que o maior atrativo do que ele denomina “amizades de Facebook" é aparentemente maior facilidade de se desconectar, de romper os vínculos. Com isto, conforme indica Velloso (2016), acabamos entrando em um estado ambíguo de solidão e multidão, de segurança e liberdade. A personagem Lacie expressa nitidamente esta expressão de ambiguidade, por tentar

\footnotetext{
${ }^{5}$ O Projeto Fronteiras do Pensamento propõe uma profunda análise da contemporaneidade e das perspectivas para o futuro, promovendo conferências internacionais e desenvolvendo conteúdos múltiplos com pensadores, artistas, cientistas e líderes em seus campos de atuação, abordando de forma interdisciplinar, o complexo panorama mundial. Maiores informações em: <http://www.fronteiras.com/>.

${ }^{6}$ Fonte: <https://bit.ly/2TKtDJB>. Acesso em: 2 set. 2018.
} 
todo o tempo criar imagens e aparências, reflexos/irrefletidos de si pensando, primordialmente, nas avaliações que recebe dos grupos com quem convive.

Assim, a partir do episódio Queda Livre apresentamos nossos esforços de compreender o quanto a relação das pessoas com os artefatos tecnológicos conectados à internet vem ressignificando a forma como vimos produzimos novos sentidos culturais com outras/os usuárias/os geograficamente dispersas/os. Um dos aspectos que merecem nossa atenção ao discutirmos a série Black Mirror é a questão da visibilidade e da privacidade. Estamos lidando com um contexto no qual todas as nossas ações cotidianas são vistas, avaliadas e mensuradas para que, deste modo, possamos ser mais ou menos aceitos por nossos pares.

Com isso, que possamos reencontrar com nossa humanidade e suas mais diversas expressões de afeto e desejo promovidas pelo encontro com o outro, mediado pelas redes sociais. Que esse encontro seja convidativo a outras formas de conhecer o mundo, impulsionando os sujeitos a engajarem-se colaborativamente na produção e no compartilhamento de informações que não caminhem meramente na busca desenfreada pelas "curtidas". Que possamos aprender com a experiência de Lacie, questionando o que estamos fazendo de nós mesmas/os nas redes sociais e (re)pensando o quanto a infraestrutura sociotécnica da $W e b$ potencializa novas formas de aprender-ensinar com a/o outra/o.

O cenário de comunicação ubíqua representado neste episódio evidencia que todas as personagens encontram-se imersas na cibercultura, interagindo mediante um número-sem-fim de telas, interfaces. Dessa forma, estamos tratando de dispositivos dotados de conectividade que permitem filmar, fotografar, registrar, produzir e compartilhar, aspectos que representam os usos dos objetos culturais que, distribuídos como nós em redes, atuam com poder de agência na construção das subjetividades. Que essa nova paisagem cultural mediada pelo digital em rede nos permita tecer reflexões profícuas para uma melhor compreensão das práticas sociais contemporâneas potencializadas pela relação que está sendo estabelecida com as redes sociais online. Por fim, que o sistema de avaliação vivenciado por Lacie em Queda Livre seja um alerta para que possamos transcender todo e qualquer tipo de avaliação que porventura seja implementado na rede, buscando cultivar relações sociais e afetivas com outras/os internautas pelo simples prazer pela partilha de saberes. 


\section{Referências}

BRAGA, R. S.; EVANGELO, N. S. “MEEOOO, ISSO É MUITO BLACK MIRROR”: A nota da Uber como punição do comportamento social na sociedade da vigilância distribuída. In: ENCONTRO ANUAL DA ASSOCIAÇÃO NACIONAL DOS PROGRAMAS DE PÓS-GRADUAÇÃO EM COMUNICAÇÃO (Compós), 26., 2017, São Paulo. Anais... São Paulo: Compós, 2017. 17p.

BRAZ, T. J. G.; MONTE, G. O.; CARVALHO, J. L. Black Mirror e a sociedade das avaliações: um estudo de caso do aplicativo Uber. In: CONGRESSO BRASILEIRO DE CIÊNCIAS DA COMUNICAÇÃO (Intercom), 40., 2017, Curitiba. Anais... Curitiba: Intercom, 2017, 12p.

COUTO JUNIOR, D. R. Cibercultura, juventude e alteridade: aprendendo-ensinando com o outro no Facebook. Jundiaí: Paco Editorial, 2013.

COUTO JUNIOR, D. R. Educação e cibercultura: ensinar e aprender com as imagens digitais nos processos comunicacionais na/da internet. Informática na Educação: teoria \& prática, Porto Alegre, v. 18, n. 1, p. 37-50, jan./jun. 2015.

COUTO JUNIOR, D. R. Marcas da abjeção expressas em conversas sobre heteronormatividade com jovens no Facebook: em defesa de uma pedagogia queer. 2017. 290 f. Tese (Doutorado em Educação) - Programa de Pós-graduação em Educação, Universidade do Estado do Rio de Janeiro, Rio de Janeiro, 2017.COUTO JUNIOR, D. R.; OSWALD, M. L. M. B. Cibercultura, juventudes e heteronormatividade: ativismo e resistência no Facebook. Revista Debates, Porto Alegre, v. 11, n. 2, p. 153-174, maio/ago. 2017.

D'ÁVILA, C.; SANTOS, E. Imagens voláteis e formação de professorxs: dispositivos tecnológicos e lúdicos para as práticas pedagógicas. Revista Entreideias, Salvador, v. 3, n. 2, p. 113-127, jul./dez. 2014.

DEBORD, G. A sociedade do espetáculo. Rio de Janeiro: Contraponto, 1997.

ECO, U. Apocalípticos e integrados. 5.ed. São Paulo: Editora Perspectiva, 1993.

FANTIN, M. Crianças, dispositivos móveis e aprendizagens formais e informais. Educação Temática Digital-ETD, Campinas, v. 20, n. 1, p. 66-80, jan./abr. 2017.

FERREIRA, H. M. C. Dinâmicas de uma juventude conectada: a mediação dos dispositivos móveis nos processos de aprender-ensinar. 2014. 272 f. Tese (Doutorado em Educação) Programa de Pós-graduação em Educação, Universidade do Estado do Rio de Janeiro, Rio de Janeiro, 2014.

FERREIRA, H. M. C.; COUTO JUNIOR, D. R. Juventudes, educação e cidade: a mediação dos dispositivos móveis de comunicação nos processos de aprender-ensinar. Textura, Canoas, v. 20, n. 44, p. 108-129, set/dez. 2018.

JENKINS, H. Cultura da convergência. 2. ed. São Paulo: Aleph, 2009.

JENKINS, H.; GREEN, J.; FORD, S. Cultura da conexão. São Paulo: Aleph, 2014. 
JENSEN, K. B. Media convergence: the three degrees of network, mass, and interpersonal communication. New York: Routledge, 2010.

JOBIM E SOUZA, S. O olho e a câmera: desafios para a educação na época da interatividade virtual. Revista Advir, Rio de Janeiro, n. 15, p. 75-81, set. 2002.

KEEN, A. Vertigem digital: por que as redes sociais estão nos dividindo, diminuindo e desorientando. Rio de Janeiro: Zahar, 2012.

KIRN, W. Little Brother is watching. In: The New York Times, out. 2010. Disponível em: $<$ https://nyti.ms/21R7rOM>. Acesso em: 4 maio 2018.

KIRKPATRICK, D. O efeito Facebook: os bastidores da história da empresa que conecta o mundo. Rio de Janeiro: Intrínseca, 2011.

LEMOS, A. Celulares, funções pós-midiáticas, cidade e mobilidade. Revista Brasileira de Gestão Urbana, Curitiba, v. 2, n. 2, p. 155-166, jul./dez. 2010.

LEMOS, A. Cidade e mobilidade: telefones celulares, funções pós-massivas e territórios informacionais. Matrižes, São Paulo, v. 1, n. 1, p. 121-137, 2007.

LEMOS, A. Isso (não) é muito Black Mirror: passado, presente e futuro das tecnologias de informação e comunicação. Salvador: EDUFBA, 2018.

LIMA, A. N. G.; FERNANDES, A. W. G. R. Através do espelho negro: a sociedade segundo a série Black Mirror. In: CONGRESSO DE CIÊNCIAS DA COMUNICAÇÃO NA REGIÃO NORDESTE (Intercom), 18., 2016, Caruaru. Anais... Caruaru: Intercom, 2016, $14 \mathrm{p}$.

LOURO, G. L. Conhecer, pesquisar, escrever... Educação, Sociedade e Culturas, Porto, v. 1, n. 25, p. 235-245, 2007.

MADEIRA, V. S.; SILVA, B. K. S.; RIOS, J. R. A. C. Reflexos da sociedade contemporânea: uma análise do episódio Nosedive, da série Black Mirror. In: CONGRESSO BRASILEIRO DE CIÊNCIAS DA COMUNICAÇÃO (Intercom), 40., 2017, Curitiba. Anais... Curitiba: Intercom, 2017, 11p.

MAFFESOLI, M. "Net-ativismo": do mito tradicional à cibercultura pós moderna. DI FELICE, Massimo; PEREIRA, E.; ROZA, E. (Org.). Net-ativismo: redes digitais e novas práticas de participação. Campinas, SP: Papirus, 2017. p.39-52.

PRETTTO, N. L; ASSIS, A. Cultural digital e educação: redes já! In: PRETTTO, N. L.; SILVEIRA, S. A. (Org.). Além das redes de colaboração: internet, diversidade cultural e tecnologias do poder. Salvador: EDUFBA, 2008, p. 75-83.

PRIMO, A. Interações mediadas e remediadas: controvérsias entre as utopias da cibercultura e a grande indústria midiática. In: PRIMO, A. (Org.). Interações em rede. Porto Alegre: Editora Sulina, 2013, p. 13-32.

RECUERO, R. Curtir, compartilhar, comentar: trabalho de face, conversação e redes sociais no Facebook. Verso e Reverso, São Leopoldo, v. 28, n. 68, p. 114-124, maio/ago. 2014. 
RECUERO, R. Atos de ameaça à face e à conversação em redes sociais da internet. In: PRIMO, A. (Org.). Interações em rede. Porto Alegre: Editora Sulina, 2013, p. 51-69.

SANTAELLA, L. Linguagens líquidas na era da mobilidade. São Paulo: Paulus, 2007.

SANTAELLA, L. Desafios da ubiquidade para a educação. Revista Ensino Superior, Unicamp, v. 9, p. 19-28, 2013.

SANTAELLA, L. Aprendizagem ubíqua. In: MILL, D. (Org.). Dicionário crítico de educação e tecnologias e de educaşão a distância. São Paulo: Papirus, 2018, p. 44-46.

SANTOS, E.; CARVALHO, F. S. P. Autorais partilhadas na interface cidade-redes digitais. Interfaces Cientificas - Educação, Aracaju, v. 6, n. 3, p. 29-40, jun. 2018.

SANTOS, E.; WEBER, A. Educação e cibercultura: aprendizagem ubíqua no currículo da disciplina didática. Revista Diálogo Educacional, Curitiba, v. 13, n. 38, p. 285-302, jan./abr. 2013.

SIBILIA, P. O homem pós-orgânico: a alquimia dos corpos e das almas à luz das tecnologias digitais. 2.ed. Rio de Janeiro: Contraponto, 2015.

SILVA, B.; ALVES, E. J. Aprendizagem na cibercultura: um novo olhar sobre as Tecnologias de Informação e Comunicação digital no contexto educativo ubíquo. Interfaces Científicas Educação, Aracaju, v. 6, n. 3, p. 17-28, jun. 2018.

TRENTO, F. B.; VENANZONI, T. S. Subjetividade, controle e ubiquidade midiática: o seriado Black Mirror. In: CONGRESSO DE CIÊNCIAS DA COMUNICAÇÃO NA REGIÃO SUDESTE (Intercom), 18., 2013, Bauru. Anais... Bauru: Intercom, 2013, 15p.

VELLOSO, L. Tão perto e tão longe: sobre [i]mobilidades na sociedade de consumidores. Revista Espaço Acadêmico, Maringá, v. 16, p. 60-70, 2016.

WEBER, A.; DOS SANTOS, R.; SANTOS, E. Caiu na rede é peixe: o currículo no contexto das redes sociais. Conhecimento \& Diversidade, Niterói, v. 4, n. 8, p. 56-75, 2013.

RECEBIDO: $19 / 06 / 2019$

APROVADO: 22/08/2019
RECEIVED: 06/19/2019

APPROVED: 08/22/2019
RECIBIDO: $19 / 06 / 2019$

APROBADO: 22/08/2019 